This document is confidential and is proprietary to the American Chemical Society and its authors. Do not copy or disclose without written permission. If you have received this item in error, notify the sender and delete all copies.

\title{
Magnetoelectric coupling springing up in molecular ferroelectric: [N(C2H5)3CH3][FeCl4]
}

\begin{tabular}{|r|l|}
\hline Journal: & Inorganic Chemistry \\
\hline Manuscript ID & Draft \\
\hline Danuscript Type: & Article \\
\hline Author: & n/a \\
\hline Complete List of Authors: & $\begin{array}{l}\text { Burazer, Sanja; Institut Ruđer Bošković } \\
\text { Popovic, Jasminka; Institut Ruder Boskovic, Division for Materials Physics } \\
\text { Jaglicic, Zvonko; Instituta za matematiko fiziko in mehaniko, Dep. of } \\
\text { Physics } \\
\text { Jagodic, Marko; Instituta za matematiko fiziko in mehaniko, } \\
\text { Saantić, Ana; Institut Ruđer Bošković Zavod za kemiju materijala } \\
\text { Altomare, Angela; Bari, Istituto di Cristallografia - Sede di } \\
\text { Cuocci, Corrado; Universita degli Studi di Bari Aldo Moro, Istituto di } \\
\text { Cristallografia (IC-CNR) } \\
\text { Corriero, Nicola; Institute of Crystallography National Research Council } \\
\text { Vrankic, Martina; Institut Ruder Boskovic, }\end{array}$ \\
\hline
\end{tabular}

\section{SCHOLARONE \\ Manuscripts}




\title{
Magnetoelectric coupling springing up in molecular
}

\author{
ferroelectric: $\left[\mathrm{N}\left(\mathrm{C}_{2} \mathrm{H}_{5}\right)_{3} \mathrm{CH}_{3}\right]\left[\mathrm{FeCl}_{4}\right]$
}

Sanja Burazer,a Jasminka Popović, ,ab Zvonko Jagličić,c,d Marko Jagodič,c Ana Šantić,e

Angela Altomare, ${ }^{f}$ Corrado Cuocci, ${ }^{f}$ Nicola Corriero ${ }^{f}$ and Martina Vrankić $a, b,{ }^{*}$

a Division of Materials Physics, Ruđer Bošković Institute, Bijenička 54, 10000 Zagreb,

Croatia.

b Center of Excellence for Advanced Materials and Sensing Devices, Ruđer Bošković

Institute, Bijenička 54, 10000 Zagreb.

c Institute of Mathematics, Physics and Mechanics, Jadranska 19, 1000 Ljubljana,

Slovenia. 
d Faculty of Civil and Geodetic Engineering, University of Ljubljana, Jamova cesta 2,
1000 Ljubljana, Slovenia.
e Division of Materials Chemistry, Ruđer Bošković Institute, Bijenička 54, 10000 Zagreb,

Croatia.

f Institute of Crystallography-CNR, via Amendola 122/o, 70126 Bari, Italy.

Keywords: improper ferroelectric, paraelectric-to-ferroelectric phase transition, dielectric permittivity, magnetoelectric coupling, symmetry-breaking, structure determination, Rietveld refinement

\section{Abstract}

A molecule-based ferroelectric triethylmethylammonium tetrachloroferrate(III)

$\left(\left[\mathrm{N}\left(\mathrm{C}_{2} \mathrm{H}_{5}\right)_{3} \mathrm{CH}_{3}\right]\left[\mathrm{FeCl}_{4}\right]\right)$ powder was designed as multifunctional material exhibiting excellent multiple bistability. Prepared by slow evaporation method at room temperature, the compound crystallizes in the non-centrosymmetric assembly of hexagonal symmetry 
$\left(P 6_{3} m c\right.$ space group) which undergoes a reversible temperature-triggered phase transition pinpointed at $363 \mathrm{~K}$ to the centrosymmetric packing within $P 6_{3} / \mathrm{mmc}$ space group. Aside from the inseparable role of the symmetry-breaking process smoothly unveiled from the X-ray powder diffraction data, a striking change in the dielectric permittivity observed during the paraelectric-to-ferroelectric phase transition directly discloses the bistable dielectric behavior - an exceptionally high increase in the dielectric permittivity of about $360 \%$ at $100 \mathrm{kHz}$ across the heating and cooling cycles is a direct proof showing the highly desirable stimuli-responsive electric ordering in this improper ferroelectric architecture. Due to the magnetically modulated physical properties resulting in the coupling of magnetic and electric orderings, the flexible assembly of $\left[\mathrm{N}\left(\mathrm{C}_{2} \mathrm{H}_{5}\right)_{3} \mathrm{CH}_{3}\right]\left[\mathrm{FeCl}_{4}\right]$ could be used to boost the design and development of novel magnetoelectric devices.

\section{INTRODUCTION}


Targeted quest for high-performance materials that integrate the advantages of organic and inorganic components assembled within a single-phase molecular system has triggered many researches to steer upon establishing the reproducible synthetic protocols to prepare molecular ferroelectrics with multiple bistabilities. The versatility of these molecular systems reflects in rich physical properties such as pyroelectricity, piezoelectricity and nonlinear optical activity. ${ }^{1}$ In particular, the unprecedented novel characteristics of such organic-inorganic hybrid structures that tunably combine magnetism of metal ions with organic ferroelectricity ${ }^{2-7}$ arising from the reversible phase transitions and switchable dielectric functionalities springed up by the order-disorder motions of molecular structures, play an important role in design of novel electrically controlled spintronic and optoelectronic devices ${ }^{8-10}$. Ultimately, the existence of the crosscoupling between magnetic and ferroelectric order parameters, manifesting through the magnetoelectric (ME) responses, resulted in quite a few well-designed key examples, proving a direct interlink between rich ME phenomena and a range of practical applications. ${ }^{5,11-18}$ The first organic-inorganic hybrid material with multiple bistable characteristics was reported by the Xiong group who successfully prepared 
triethylmethylammonium tetrabromoferrate(III) $\left(\left[\mathrm{N}\left(\mathrm{C}_{2} \mathrm{H}_{5}\right)_{3} \mathrm{CH}_{3}\right]\left[\mathrm{FeBr}_{4}\right]\right) .{ }^{5}$ This potential molecular multiferroic exhibiting attractive physical properties shows a strong coupling between ferroelectric and magnetic anomalies when approaching phase transition (at $T_{\mathrm{c}}$ $=360 \mathrm{~K})$ that is accompanied by the symmetry-breaking. Different molecular dynamics of the polar triethylmethylammonium cation, closely related to the observed phase transition, are one of the main factors driving the phase transition process and the switchable dielectric property of $\left[\mathrm{N}\left(\mathrm{C}_{2} \mathrm{H}_{5}\right)_{3} \mathrm{CH}_{3}\right]\left[\mathrm{FeBr}_{4}\right]$. Intensive research on this rapidly booming field, done by the same research group, resulted in the discovery of imidazolium periodate, $(\mathrm{Im}) \mathrm{IO}_{4}$, as a new improper molecular ferroelectric undergoing a paraelectricto - ferroelectric phase transition at $T_{\mathrm{c}}=310 \mathrm{~K}$ with a large thermal hysteresis loop bistability. ${ }^{19}$ However, besides the rational synthesis of molecular ferroelectrics with controllable ME properties, one of the critical obstacles still challenging researchers is how to single out the molecular ferroelectrics from the numerous crystalline materials. One of the pivotal features certainly is related to the relationship between the symmetrybreaking during the phase transition and resulting functional properties, thus highlighting a mandatory role of structural investigations in the course of ME response tailoring. 
Enlightened by the above-referenced examples, we deliver the novel molecular

ferroelectric, triethylmethylammonium tetrachloroferrate(III) $\left(\left[\mathrm{N}\left(\mathrm{C}_{2} \mathrm{H}_{5}\right)_{3} \mathrm{CH}_{3}\right]\left[\mathrm{FeCl}_{4}\right]\right)$ by capturing the unique physical functionalities through temperature-triggered X-ray powder diffraction (XRPD), electrical and magnetic measurements. A reversible paraelectric-toferroelectric phase transition of the title molecular assembly at $\sim 363 \mathrm{~K}$ accompanied by the symmetry-breaking process, switchable dielectric behavior and the presence of coupled magnetic and electric ordering undoubtedly corroborates that $\left[\mathrm{N}\left(\mathrm{C}_{2} \mathrm{H}_{5}\right)_{3} \mathrm{CH}_{3}\right]\left[\mathrm{FeCl}_{4}\right]$ is a new and prosperous member of the bistable molecular ferroelectrics' family bolstering the future design of ME elements. In this regard, our results that highlight the outstanding progressive increase of dielectric permittivity above $T_{\mathrm{c}}=363 \mathrm{~K}$ for $\sim 360 \%$ at $100 \mathrm{kHz}$ and symmetry-breaking process tackled through the crystallographic information extracted from solely XRPD data, rank this molecular ferroelectric ahead its structural analogue $\left[\mathrm{N}\left(\mathrm{C}_{2} \mathrm{H}_{5}\right)_{3} \mathrm{CH}_{3}\right]\left[\mathrm{FeBr}_{4}\right]_{5}$. 


\section{EXPERIMENTAL SECTION}

2.1. Synthetic procedures. All the chemicals were of reagent grade and were used without any further purification. Triethylmethylammonium tetrachloroferrate(III) $\left(\left[\mathrm{N}\left(\mathrm{C}_{2} \mathrm{H}_{5}\right)_{3} \mathrm{CH}_{3}\right]\left[\mathrm{FeCl}_{4}\right]\right)$ was prepared by mixing aqueous solutions of anhydrous iron(III) chloride $\left(\mathrm{FeCl}_{3} ;\right.$ Fischer Chemical, $97 \%$ purity, $\left.0.32 \mathrm{~g}, 2 \mathrm{mmol}\right)$ and triethylmethylammonium chloride $\left(\left(\mathrm{C}_{2} \mathrm{H}_{5}\right)_{3} \mathrm{~N}(\mathrm{Cl}) \mathrm{CH}_{3} \cdot \mathrm{H}_{2} \mathrm{O} ; \mathrm{TCl}\right.$ Chemicals, $97 \%$ purity, $0.30 \mathrm{~g}, 2 \mathrm{mmol}$ ). The solution was left stirring at RT for $2 \mathrm{~h}$ and filtered afterward. Irregularly shaped, fragile single crystals of a dark yellow color started to appear from the solution of salt within 2 weeks of slow evaporation at RT. Several single crystals were removed from the supernatant, washed with methanol and dried at RT, while the rest of the precipitates were ground into a fine yellow powder.

2.2. X-ray powder diffraction. XRPD measurements were performed on the finely grounded powder to reveal the structural features due to the encountered obstacles while trying to obtain a good quality single-crystal. The XRPD data at room temperature (RT) were collected in reflection mode with monochromated CuKa radiation $(\lambda=1.54056 \AA)$ on a Bruker D8 Advance Bragg-Brentano diffractometer using a step size of $0.013^{\circ}$ in 
the $2 \theta$ range between $10^{\circ}$ and $60^{\circ}$. Crystal structure determination of $\left[\mathrm{N}\left(\mathrm{C}_{2} \mathrm{H}_{5}\right)_{3} \mathrm{CH}_{3}\right]\left[\mathrm{FeCl}_{4}\right]$ at RT was performed using direct-space simulated-annealing approaches within the EXPO software ${ }^{20}$ followed by the Rietveld refinement using the GSAS suite 21,22 .

The XRPD patterns at high temperature were measured using a Philips PW1880 diffractometer having a high-temperature $(\mathrm{HT})$ attachment and a proportional detector, and utilizing monochromatic CuKa X-ray source $(\lambda=1.54056 \AA)$. The temperature program was initiated at RT and diffractograms were collected at the $363 \mathrm{~K}$ within two cycles. After the first heating cycle, the sample was cooled down to $295 \mathrm{~K}$ and a new scan was collected to ensure the reversibility of observations. Indexing and space group determination of the HT XRPD pattern were performed using the EXPO software ${ }^{20}$. The Le Bail intensity extraction applied to the HT phase was completed using the X'Pert HighScore Plus 4.1 program $^{23}$.

2.3. Dielectric measurements. The complex dielectric permittivity was measured by impedance spectroscopy (Novocontrol Alpha-N dielectric analyzer) at $100 \mathrm{kHz}$ and 600 $\mathrm{kHz}$ in heating from RT to $403 \mathrm{~K}$ and subsequent cooling down to RT. For the electrical 
contact, the gold electrodes of $4 \mathrm{~mm}$ in diameter were sputtered onto both sides of the powder pressed pellets using the SC7620 Sputter Coater (Quorum Technologies).

2.4. Magnetic characterizations. The magnetic susceptibilities of $\left[\mathrm{N}\left(\mathrm{C}_{2} \mathrm{H}_{5}\right)_{3} \mathrm{CH}_{3}\right]\left[\mathrm{FeCl}_{4}\right]$ powder and single-crystal samples were studied between $2 \mathrm{~K}$ and $390 \mathrm{~K}$ in the magnetic field of $\mathrm{H}=500 \mathrm{Oe}$ and the magnetization was measured at several constant temperatures between $\mathrm{H}= \pm 50 \mathrm{kOe}$ with a Quantum Design MPMS-XL-5 SQUID magnetometer. The measured data were corrected for a sample holder contribution and a temperature-independent Larmor diamagnetism of the core electrons obtained from the Pascal's tables ${ }^{24}$.

\section{RESULTS AND DISCUSSION}

3.1. Structural features. The resulting dark yellow polycrystals had a single phase XRPD pattern at ambient temperature. Indexing of the powder pattern using N-TREOR09 ${ }^{20}$ led to plausible hexagonal symmetry with initial lattice parameters $a=8.1224(6) \AA$ and $c=$ $13.1569(16) \AA$ having a total volume of $751.72(12) \AA^{3}$ and $Z=2$. The space group was determined as polar, non-centrosymmetric ${ }^{P 6_{3}} m c$ of a $6 \mathrm{~mm}$ point group $\left(C_{6 v}^{4}\right.$, Laue 
symmetry: $6 / \mathrm{mmm}$ ), with symmetry elements analogues to those of ferroelectric $\left[\mathrm{N}\left(\mathrm{C}_{2} \mathrm{H}_{5}\right)_{3} \mathrm{CH}_{3}\right]\left[\mathrm{FeBr}_{4}\right]^{5}$ reported by Cai et al. The clear lack of the spatial-inversion symmetry present herein is generally a first sharp-cut premise useful in predicting the physical features of ferroelectrics..$^{25,26}$ The starting model for the simulated-annealing optimization was built up using an ethylmethylammonium fragment without any substitution of hydrogen atoms on carbon atoms and a $\mathrm{Fe}-\mathrm{Cl}$ fragment, modeled as a rigid body with 11 degrees of freedom. The organic part of the building block was taken out from the $\mathrm{C}_{11} \mathrm{H}_{38} \mathrm{~B}_{18} \mathrm{CoNO}$ structure reported by Petrina et al. ${ }^{27}$ while the inorganic fragment originated from the $\mathrm{FeCl}_{2}$ structure published by Vettier et al. ${ }^{28}$. In the final step, obtained structural model was refined by the Rietveld method with excellent agreement between observed and calculated profiles achieved for the title compound at $293 \mathrm{~K}\left(a=8.12781(10) \AA, c=13.16766(24) \AA, V=753.33(2) \AA^{3}, R w p=\right.$ $2.13 \%, R p=1.32 \%)($ Figure $1 \mathrm{a})$. The final structural parameters for the hexagonal $\left[\mathrm{N}\left(\mathrm{C}_{2} \mathrm{H}_{5}\right)_{3} \mathrm{CH}_{3}\right]\left[\mathrm{FeCl}_{4}\right]$ phase at ambient temperature are summarized in Table 1, along with the reliability factors confirming the validity of the refinement. The refinement procedure included a refinement of background parameters, zero shift, lattice parameters 
$a$ and $c$, atomic position parameters, and temperature factors for all present atoms. Background parameters were refined using the Chebyschev polynomial function of the first kind with 8 coefficients. Diffraction-line profile parameters were refined employing a multi-term Simpson's rule integration described by Howard ${ }^{29}$ and Thompson et al. ${ }^{30}$. The rigid body constraints were applied on both, organic and inorganic molecular fragments during the structure refinement.

The hexagonal crystal structure of $\left[\mathrm{N}\left(\mathrm{C}_{2} \mathrm{H}_{5}\right)_{3} \mathrm{CH}_{3}\right]\left[\mathrm{FeCl}_{4}\right]$ at $\mathrm{RT}$ is illustrated in Figures $1 \mathrm{~b}$, $c$ and $d$. The asymmetric unit depicted in Figure $1 \mathrm{~b}$ features triethylmethylammonium cation $\left(\left[\mathrm{N}\left(\mathrm{C}_{2} \mathrm{H}_{5}\right)_{3} \mathrm{CH}_{3}\right]^{+}\right)$and tetrachloroferrate anion $\left(\left[\mathrm{FeCl}_{4}\right]^{-}\right)$that both lie on the hexagonal axis, alike as for the isostructural ferroelectrics $\left[\mathrm{N}\left(\mathrm{C}_{2} \mathrm{H}_{5}\right)_{3} \mathrm{CH}_{3}\right]\left[\mathrm{FeBr}_{4}\right]^{5}$ and $\left[\mathrm{N}\left(\mathrm{C}_{2} \mathrm{H}_{5}\right)_{4}\right]\left[\mathrm{FeCl}_{4}\right]^{31}$. The nitrogen atom $\mathrm{N} 1$ and carbon atom $\mathrm{C} 1$ are located on the threefold symmetry axis, while the carbon atoms $\mathrm{C} 2$ and $\mathrm{C} 3$ are aligned along the mirror planes and are arranged in the way that they form a trigonal pyramidal shape about N1. Tetragonal distortion is present in the $\left[\mathrm{FeCl}_{4}\right]^{-}$anion as one deviates from the perfect tetrahedral symmetry; $\mathrm{Fe} 1$ and one chlorine atom $\mathrm{Cl} 2$ are placed on sites of $3 m$ symmetry, while other three linked chlorine atoms $\mathrm{Cl} 1$ lie on the mirror planes. Additionally, the $\mathrm{Fe}-$ 
Cl bond lengths elongated to $2.180(5) \AA$ and 2.209(7) $\AA$, respectively, are close to values reported by Evans et al. for isostructural $\left[\mathrm{N}\left(\mathrm{C}_{2} \mathrm{H}_{5}\right)_{4}\right]\left[\mathrm{FeCl}_{4}\right]^{31}$ single crystal. However, these length elongations are not accompanied by the regular tetrahedral $\mathrm{Cl}-\mathrm{Fe}-\mathrm{Cl}$ bond angles but adopt slightly distorted values of $112.71(19)^{\circ}$ and $105.99(22)^{\circ}$, respectively.

Table 1. Summary of resulting structural parameters and reliability factors for the $\left[\mathrm{N}\left(\mathrm{C}_{2} \mathrm{H}_{5}\right)_{3} \mathrm{CH}_{3}\right]\left[\mathrm{FeCl}_{4}\right]$ sample obtained from the Rietveld refinement of laboratory XRPD data collected at $293 \mathrm{~K}(\lambda=1.54056 \AA)$ with the e.s.d.'s in the parentheses.

\begin{tabular}{|c|c|c|c|c|c|c|c|c|c|c|}
\hline Atom & $R_{\mathrm{p}}(\%)$ & $R_{\mathrm{wp}}(\%)$ & $\chi^{2}$ & $a(\AA)$ & $b(\AA)$ & $c(\AA)$ & & $\begin{array}{l}\text { Nyck. } \\
\text { osition }\end{array}$ & symmetry & $\mathrm{U}_{\text {iso }}\left(\AA^{2}\right)$ \\
\hline $\mathrm{Fe} 1$ & \multirow{7}{*}{1.32} & \multirow{7}{*}{2.13} & \multirow{7}{*}{0.72} & 1.0000000 & 1.0000000 & $0.5703(5)$ & 2 & $a$ & $3 m$ & $0.010(3)$ \\
\hline $\mathrm{Cl1}$ & & & & $1.14883(32)$ & $0.85117(32)$ & $0.6160(7)$ & 6 & & $m$ & $0.015(3)$ \\
\hline $\mathrm{Cl} 2$ & & & & 1.0000000 & 1.0000000 & 0.4026180 & 2 & & $3 m$ & $0.018(6)$ \\
\hline N1 & & & & 1.3333000 & 0.6667000 & $0.3223(12)$ & 2 & $b$ & $3 m$ & $0.13(2)$ \\
\hline $\mathrm{C} 1$ & & & & 1.3333000 & 0.6667000 & $0.2061(12)$ & 2 & $b$ & $3 m$ & $0.05(2)$ \\
\hline $\mathrm{C} 2$ & & & & $1.1902(19)$ & $0.5951(9)$ & $0.3793(12)$ & 6 & & $m$ & $0.10(1)$ \\
\hline $\mathrm{C} 3$ & & & & $1.0001(12)$ & $0.5000(9)$ & $0.3628(12)$ & 6 & $c$ & $m$ & $0.079(9)$ \\
\hline \multicolumn{11}{|c|}{ Molecular dimensions in anion and cation $\left(\AA,{ }^{\circ}\right)$} \\
\hline $\mathrm{Fe} 1-\mathrm{Cl}$ & \multirow{2}{*}{\multicolumn{2}{|c|}{$\begin{array}{l}2.180(5) \\
2.209(7)\end{array}$}} & & $\mathrm{N} 1-\mathrm{C} 1$ & $1.53008(3)$ & \multirow{2}{*}{\multicolumn{4}{|c|}{$\begin{array}{ll}\mathrm{C} 2-\mathrm{C} 2 & 1.745(23) \\
\mathrm{C} 2-\mathrm{C} 3 & 1.35562(2)\end{array}$}} & \\
\hline $\mathrm{Fe} 1-\mathrm{Cl} 2$ & & & & $\mathrm{~N} 1-\mathrm{C} 2 \quad 1.2$ & $56(11)$ & & & & & \\
\hline \multirow{5}{*}{\multicolumn{2}{|c|}{$\begin{array}{l}\mathrm{C} 11-\mathrm{Fe} 1-\mathrm{C} 11 \\
\mathrm{C} 11-\mathrm{Fe} 1-\mathrm{Cl} 2\end{array}$}} & \multirow{5}{*}{$\begin{array}{l}112.71(19) \\
105.99(22)\end{array}$} & & $\mathrm{C} 1-\mathrm{N} 1-\mathrm{C} 2$ & $126.7(4)$ & \multicolumn{3}{|c|}{$\mathrm{C} 2-\mathrm{C} 2-\mathrm{C} 2 \quad 60.0(0)$} & & \\
\hline & & & & $\mathrm{C} 2-\mathrm{N} 1-\mathrm{C} 2$ & $88.0(5)$ & \multirow{4}{*}{\multicolumn{2}{|c|}{$\begin{array}{l}\mathrm{C} 2-\mathrm{C} 2-\mathrm{C} 3 \\
\mathrm{C} 2-\mathrm{C} 2-\mathrm{C} 3\end{array}$}} & \multirow{2}{*}{\multicolumn{2}{|c|}{$\begin{array}{l}148.725(0) \\
148757(0)\end{array}$}} & \\
\hline & & & & $\mathrm{N} 1-\mathrm{C} 2-\mathrm{C} 2$ & $46.04(26)$ & & & & & \\
\hline & & & & $\mathrm{N} 1-\mathrm{C} 2-\mathrm{C} 2$ & $46.01(26)$ & & & \multirow{2}{*}{\multicolumn{2}{|c|}{$148.757(0)$}} & \\
\hline & & & & $\mathrm{N} 1-\mathrm{C} 2-\mathrm{C} 3$ & $134.1(4)$ & & & & & \\
\hline
\end{tabular}

R-factors defined according to those described within the GSAS manual ${ }^{21}$. 
Namely, a similar tetrahedral distortion was also found in the $\left[\mathrm{AsPh}_{4}\right]\left[\mathrm{FeCl}_{4}\right]^{32}$ and $\left[\left(\mathrm{CH}_{3}\right)_{4} \mathrm{P}\right]\left[\mathrm{FeCl}_{4}\right]^{33}$ materials. In the crystal lattice, the $\left[\mathrm{FeCl}_{4}\right]^{-}$is surrounded by six cations, showing a typical six-fold symmetry (Figure 2c). The interionic contacts in the crystal of $\left[\mathrm{FeCl}_{4}\right]^{-}$salt are between halogen atoms, $\mathrm{Cl} 1$ and $\mathrm{Cl} 2$ and carbon atoms, $\mathrm{C} 2$ of methylene groups $\left(\mathrm{C}_{\alpha}\right)$ with C2-Cl1 distances of 3.855(16) $\AA$ and C2-Cl2 distances of 4.290(7) $\mathrm{A}$.

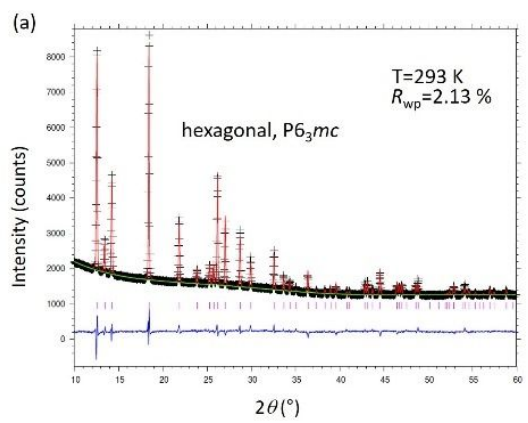

(b)

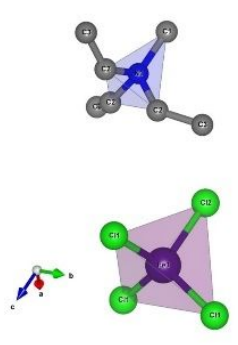

(c)

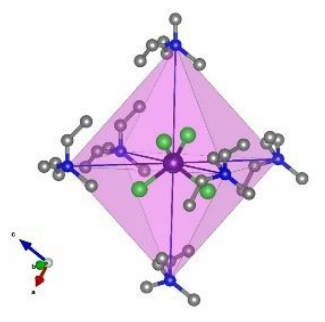

(d)

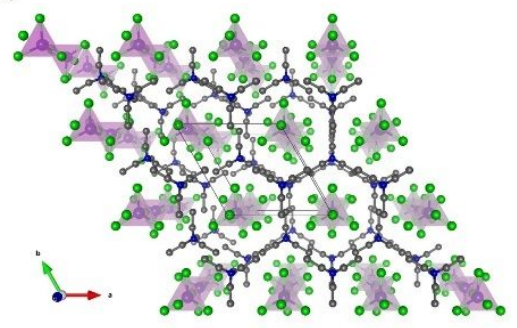

Figure 1. (a) Final observed (black crosses) and calculated (red solid line) powder diffraction profile for $\left[\mathrm{N}\left(\mathrm{C}_{2} \mathrm{H}_{5}\right)_{3} \mathrm{CH}_{3}\right]\left[\mathrm{FeCl}_{4}\right]$ sample at $293 \mathrm{~K}$ as obtained from the Rietveld refinement. The lower blue solid line in a shows the difference profiles and the purple tick marks show the reflection positions. (b) and (c) Molecular coordination environments, and (d) overview of molecular packing of $\left[\mathrm{N}\left(\mathrm{C}_{2} \mathrm{H}_{5}\right)_{3} \mathrm{CH}_{3}\right]\left[\mathrm{FeCl}_{4}\right]$ at $\mathrm{RT}$ viewed along c-axis with hydrogen atoms omitted. Prepared using VESTA $3 .{ }^{33}$ 


\begin{abstract}
A reversible, temperature-triggered structural transition from $\mathrm{RT}$ to HT phase was observed from the XRPD patterns during successive heating-cooling cycles in the range of $293 \mathrm{~K}$ and $363 \mathrm{~K}$ (Figure 2). The powder patterns collected at $293 \mathrm{~K}$ and $295 \mathrm{~K}$ showed Bragg reflections of the solely ferroelectric phase.
\end{abstract}

However, HT data obtained during the heating cycle exhibit some differences. Namely, above $363 \mathrm{~K}$, only several sharp new reflections were observed, similar to those appearing above $368 \mathrm{~K}$ for the reported $\mathrm{HT}$ phase of $\left[\mathrm{N}\left(\mathrm{C}_{2} \mathrm{H}_{5}\right)_{3} \mathrm{CH}_{3}\right]\left[\mathrm{FeBr}_{4}\right]^{5}$. Such a sharp decrease in the number of diffraction peaks is clearly an indication of a transition from the low symmetry to the high symmetry phase.$^{5,34}$ As opposed to the difficulty in obtaining the crystal structure in the paraelectric phase addressed for $\left[\mathrm{N}\left(\mathrm{C}_{2} \mathrm{H}_{5}\right)_{3} \mathrm{CH}_{3}\right]\left[\mathrm{FeBr}_{4}\right]^{5}$, a good crystallinity of the $\mathrm{HT}$ phase of $\left[\mathrm{N}\left(\mathrm{C}_{2} \mathrm{H}_{5}\right)_{3} \mathrm{CH}_{3}\right]\left[\mathrm{FeCl}_{4}\right]$ powder resulted in extracting the crystallographic information from the XRPD data. The HT powder pattern of $\left[\mathrm{N}\left(\mathrm{C}_{2} \mathrm{H}_{5}\right)_{3} \mathrm{CH}_{3}\right]\left[\mathrm{FeCl}_{4}\right]$ was indexed in hexagonal crystal system with the lattice parameters $a=8.520(2) \AA, c=7.333(1) \AA$, and $V=461.1(6) \AA^{3}$ featuring a nonpolar, 
centrosymmetric $\mathrm{PG}_{3} / \mathrm{mmc}$ space group of a $6 / \mathrm{mmm}$ point group $\left(\boldsymbol{D}_{6 \boldsymbol{h}}^{4}\right.$, Laue symmetry:

$6 / \mathrm{mmm}$ ), having a spatial inversion symmetry.

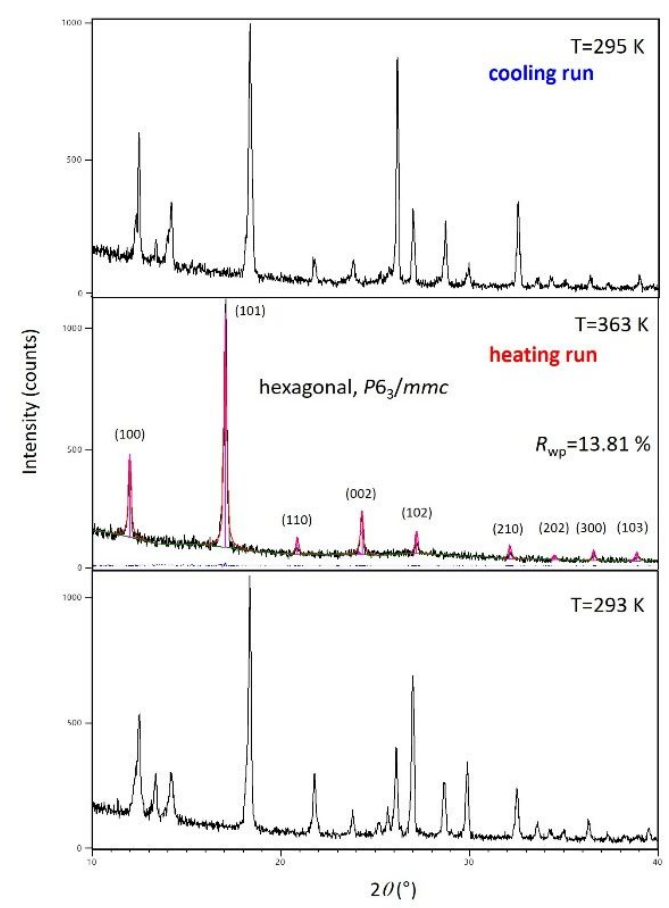

Figure 2. Reversible, temperature-induced structural transition from the noncentrosymmetric (s. g. $P 6_{3} m c$ ) to centrosymmetric (s. g. $P 6_{3} / m m c$ ) phase observed from the XRPD patterns in the range of $293 \mathrm{~K}$ and $363 \mathrm{~K}$.

Consequently, the symmetry-breaking belongs to one of the 18 uniaxial ferroelectric phase transitions and occurs with an Aizu notation of $6 / \mathrm{mmmF6} m m$ (Scheme 1). 


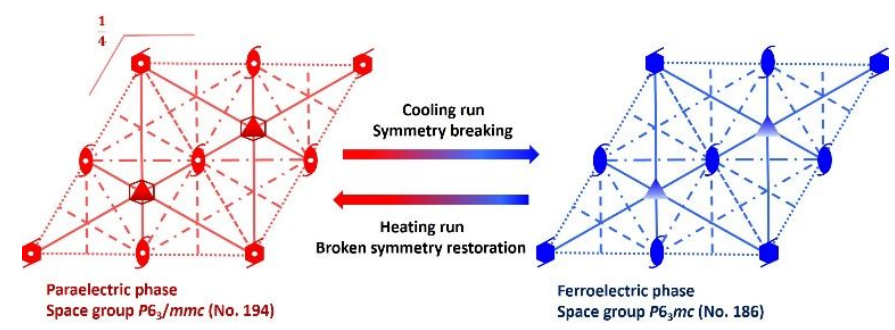

Scheme 1. Equatorial plane projection of point groups $6 / \mathrm{mmm}\left(\boldsymbol{D}_{\mathbf{6} h}^{4}\right)$ in the paraelectric phase and $6 \mathrm{~mm}\left(C_{6 v}^{4}\right)$ in the ferroelectric phase during the symmetry-breaking from HT phase to low-temperature (LT) phase.

This confirms that the phase transition of $\left[\mathrm{N}\left(\mathrm{C}_{2} \mathrm{H}_{5}\right)_{3} \mathrm{CH}_{3}\right]\left[\mathrm{FeCl}_{4}\right]$ belongs to the ferroelectric type $^{35}$. Such a result of reversible phase transitions due to the crystal symmetry transforming from paraelectric space group $P 6_{3} / m m c$ at $363 \mathrm{~K}$ to ferroelectric space group $\mathrm{Pb}_{3} \mathrm{mc}$ at $296 \mathrm{~K}$ and $295 \mathrm{~K}$, respectively, implies a group-subgroup relationship between the paraelectric and ferroelectric phases upon temperature-induced structural transition by means of a Curie symmetry principle, commonly observed in molecular ferroelectrics.

3.2. Dielectric measurements. It is a well-known fact that if the paraelectric phase belongs to the centrosymmetric point groups, the ferroelectrics are reversible, in which the direction of the spontaneous polarization can be reversed under the external electric 
field. ${ }^{1,36,37}$ In particular, the complex dielectric permittivity is sensitive to the symmetrybreaking from the paraelectric point group to the ferroelectric one and its temperature dependence, being greatly increased near the transition temperature, suggests a change in the polarity of crystal structure and is a direct sign of the transition between paraelectric and ferroelectric phase. It should be kept in mind that if a compound crystallizes in one of the 10 polar point groups at RT, the temperature-dependent complex dielectric permittivity should be measured in the temperature range of RT to below the melting point. Therefore, the temperature dependence of the complex dielectric permittivity of $\left[\mathrm{N}\left(\mathrm{C}_{2} \mathrm{H}_{5}\right)_{3} \mathrm{CH}_{3}\right]\left[\mathrm{FeCl}_{4}\right]$ was measured during heating and cooling modes to detect the symmetry-breaking as well as the phase transitions observed from the XRPD patterns. The real part of the complex dielectric permittivity, $\left(\varepsilon^{\prime}\right)$, of $\left[\mathrm{N}\left(\mathrm{C}_{2} \mathrm{H}_{5}\right)_{3} \mathrm{CH}_{3}\right]\left[\mathrm{FeCl}_{4}\right]$ measured at $100 \mathrm{kHz}$ and $600 \mathrm{kHz}$ in the range from RT and $403 \mathrm{~K}$ is shown in Figures $3 a$ and $\mathrm{b}$. 


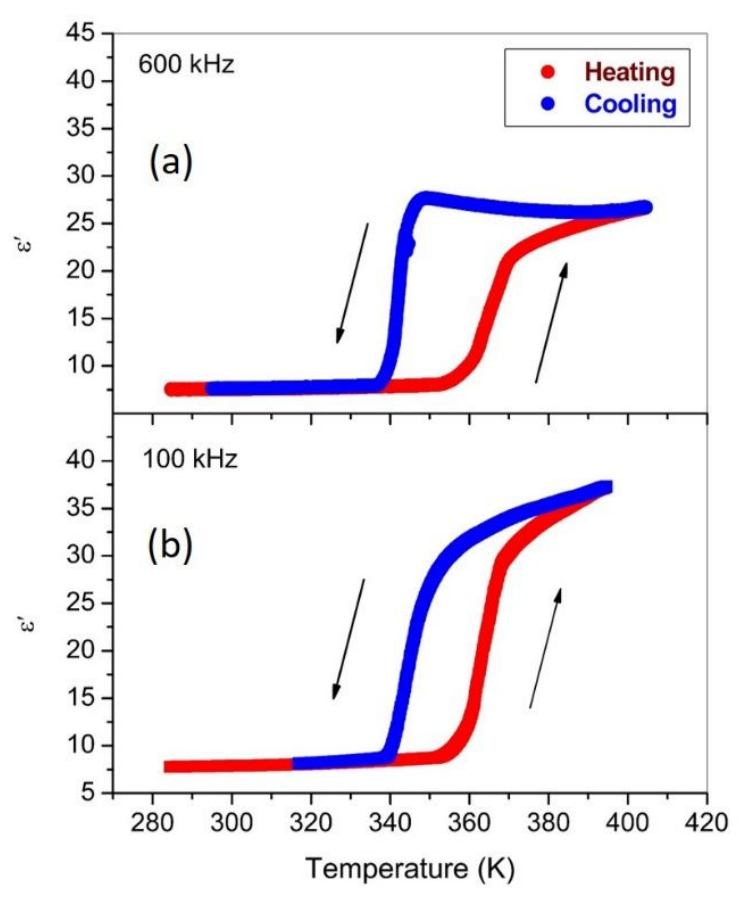

Figure 3. Temperature dependence of the real part of the complex dielectric permittivity, $\left(\boldsymbol{\varepsilon}^{\prime}\right)$, of $\left[\mathrm{N}\left(\mathrm{C}_{2} \mathrm{H}_{5}\right)_{3} \mathrm{CH}_{3}\right]\left[\mathrm{FeCl}_{4}\right]$ at (a) $600 \mathrm{kHz}$, and (b) $100 \mathrm{kHz}$ in the heating (red lines) and cooling (blue lines) modes.

At both frequencies, a step-like anomaly in the dielectric permittivity is observed at $360 \mathrm{~K}$ and $345 \mathrm{~K}$ during the heating and cooling runs, respectively. The change in the dielectric permittivity in such step-like fashion across the phase transition zone is common for the improper ferroelectric ordering 5,38 and fulfills the requirement of switchable dielectrics, distinct from the peak-like ones observed in the proper ferroelectrics. Namely, 
in the improper ferroelectrics, the polarization is not the driving parameter of the transition, but it may arise or change as a consequence of structural changes. ${ }^{38}$ The typical feature of these materials is a change in the number of atoms in the unit cell volume at phase transition as evidenced by the HT XRPD experiments in the case of $\left[N\left(\mathrm{C}_{2} \mathrm{H}_{5}\right)_{3} \mathrm{CH}_{3}\right]\left[\mathrm{FeCl}_{4}\right]$. Indeed, the transition temperature of $360 \mathrm{~K}$ is in a good agreement with the structural phase transition temperature of $363 \mathrm{~K}$ observed in the HT XRPD measurements. At temperatures below the phase transition, $\left[\mathrm{N}\left(\mathrm{C}_{2} \mathrm{H}_{5}\right)_{3} \mathrm{CH}_{3}\right]\left[\mathrm{FeCl}_{4}\right]$ sample shows a low value of the dielectric permittivity $(\approx 7.5)$, whereas above transition the dielectric permittivity increases progressively, for about $360 \%$ (at $100 \mathrm{kHz}$ ). Notably, the observed increase is significantly higher than for the $\left[\mathrm{N}\left(\mathrm{C}_{2} \mathrm{H}_{5}\right)_{3} \mathrm{CH}_{3}\right]\left[\mathrm{FeBr}_{4}\right]^{5}$ where the authors reported $\sim 40 \%$ larger dielectric value of the paraelectric phase.

3.3. Magnetic characterizations. Owing to the paramagnetic $\left[\mathrm{FeCl}_{4}\right]^{-}$anions in $\left[\mathrm{N}\left(\mathrm{C}_{2} \mathrm{H}_{5}\right)_{3} \mathrm{CH}_{3}\right]\left[\mathrm{FeCl}_{4}\right]$, it is reasonable to expect that $\left[\mathrm{N}\left(\mathrm{C}_{2} \mathrm{H}_{5}\right)_{3} \mathrm{CH}_{3}\right]\left[\mathrm{FeCl}_{4}\right]$ might possess interesting magnetic properties besides electrical one. The measurements of magnetization $M$ as a function of temperature were carried out under an applied directcurrent field of $H=500$ Oe to investigate the magnetic properties of $\left[\mathrm{N}\left(\mathrm{C}_{2} \mathrm{H}_{5}\right)_{3} \mathrm{CH}_{3}\right]\left[\mathrm{FeCl}_{4}\right]$ 
in the temperature range from $2-390 \mathrm{~K}$. The experiment showed that the susceptibility $\chi$ $=\mathrm{M} / \mathrm{H}$ monotonically increases with decreasing temperature as shown in Figure 4a. Arguably, an almost constant $\chi \cdot T$ value of $4.3 \mathrm{emu} \mathrm{K} \mathrm{mol}^{-1}$ above $70 \mathrm{~K}$ is a fingerprint of paramagnetic behavior. The effective magnetic moment can be calculated from the product $\chi \cdot T$ as $\mu_{\text {eff }}=\sqrt{\mathbf{8} \chi \boldsymbol{T}}=\mathbf{5 . 9} \mu_{\boldsymbol{B}} \cdot{ }^{39}$ This value corresponds to a high spin $\mathrm{Fe}(\mathrm{III})$ ion with quantum spin numbers $S=J=5 / 2$ and zero orbital moment $L=0.40$ Below $70 \mathrm{~K}$ the product $\chi \cdot T$ starts to decrease with decreasing temperature which can be attributed to a weak antiferromagnetic interaction between $\mathrm{Fe}(\mathrm{III})$ ions. ${ }^{41-46}$ The Curie-Wiess fit $\chi=C /(T$ $\theta$ ), for $7>70 \mathrm{~K}$ (full green line in Figure $5 \mathrm{a}$ ) gives the Curie constant $C=4.3 \mathrm{emu} \mathrm{K} \mathrm{mol}^{-1}$ in agreement with the $\mathrm{HT}$ value of the $\chi \cdot T$, and a negative Curie-Weiss temperature $\theta=-$ 2.3 K. The obtained Curie-Weiss temperature $\theta$ enables us to estimate the value of an interaction parameter $J$ between the $\mathrm{Fe}(\mathrm{III})$ nearest neighbors. Using a mean-field approximation ${ }^{47}$ we obtain $\mathrm{J} / \mathrm{kB} \approx-9 \cdot 10-2 \mathrm{~cm}^{-1}$. The indication of the antiferromagnetic interaction effective only at low temperatures ${ }^{48-51}$ can also be deduced from the shape of the measured magnetization curves obtained at $2 \mathrm{~K}, 5 \mathrm{~K}$, and $10 \mathrm{~K}$, and shown in Figure 4b. For comparison, a theoretical function based on the Brillouin function applicable for 
the non-interacting magnetic moments with spins $S=5 / 2$ at $2 \mathrm{~K}$ is shown as black dashed line. The measured magnetization at the same temperature (black squares with the full line that serve as an eye guide only) is smaller than the Brillouin function for all magnetic fields, while the value in a maximal magnetic field of $50 \mathrm{kOe}$ is close to the expected saturation magnetization of $5 \mu \mathrm{B}$.
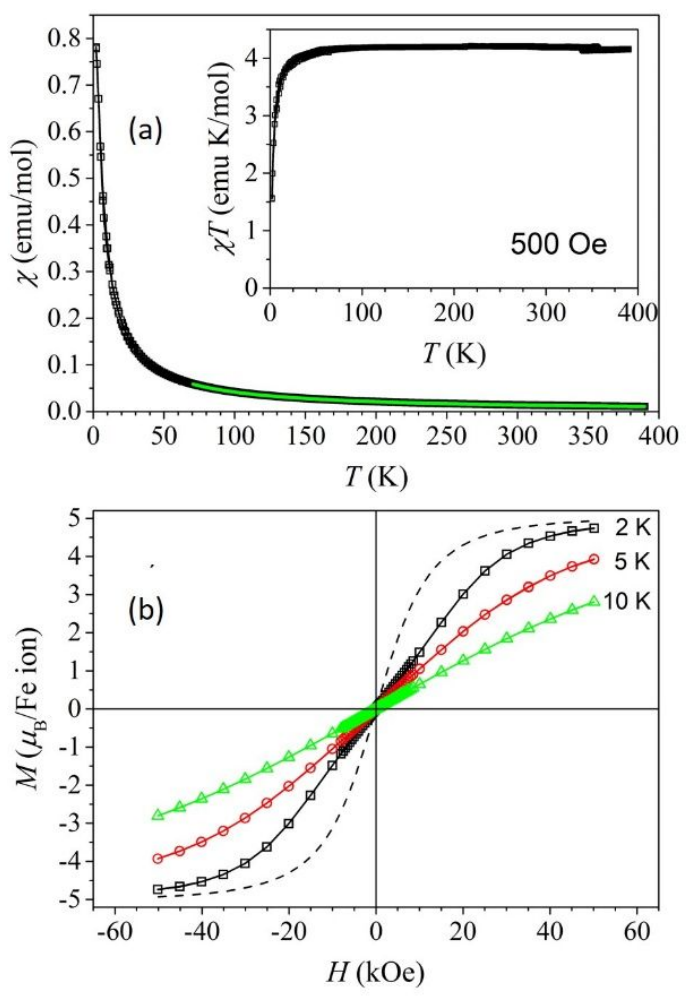

Figure 4. (a) Susceptibility $\chi$ and product $\chi \cdot T$ (inset) as a function of the temperature for $\left[\mathrm{N}\left(\mathrm{C}_{2} \mathrm{H}_{5}\right)_{3} \mathrm{CH}_{3}\right]\left[\mathrm{FeCl}_{4}\right]$ powder sample measured in magnetic field up to $500 \mathrm{Oe}$. (b) Magnetization curves at $2 \mathrm{~K}, 5 \mathrm{~K}$ and $10 \mathrm{~K}$ for $\left[\mathrm{N}\left(\mathrm{C}_{2} \mathrm{H}_{5}\right)_{3} \mathrm{CH}_{3}\right]\left[\mathrm{FeCl}_{4}\right]$ powder sample. The 
full green line in $\mathbf{a}$ is a fit with the Curie-Weiss law and the black dashed curve in $\mathbf{b}$ is a theoretical function for the non-interacting $S=5 / 2$ ions at $2 \mathrm{~K}$ calculated from the Brillouin function.

In Figure 5 a the product $\chi \cdot T$ is shown on an expanded scale in the HT range. The steeplike decrease of the $\chi \cdot T$ occurs at $T_{\text {(up) }}=356 \mathrm{~K}$ when temperature increases, while the steep-like increase of the product $\chi \cdot$ Toccurs at $T_{(\text {down })}=340 \mathrm{~K}$ on decreasing temperature. In both cases, a temperature rate of $0.2 \mathrm{~K} / \mathrm{min}$ was used. A similar thermal hysteresis has been observed in the isostructural $\left[\mathrm{N}\left(\mathrm{C}_{2} \mathrm{H}_{5}\right)_{3} \mathrm{CH}_{3}\right]\left[\mathrm{FeBr}_{4}\right]^{5}$ between $360 \mathrm{~K}$ and $370 \mathrm{~K}$. The observed thermal hysteresis confirms a reversible structural transformation and accompanies the paraelectric-to-ferroelectric phase transition.

Finally, we search for direct evidence of the ME coupling by measuring the influence of the electric field on the measured magnetization of the sample. For this purpose, a single-crystal of title compound was used. Electrodes were made by applying an electrically conductive silver paste on the opposite faces of the single crystal in such a way that the electric field applied along the crystallographic $c$ axis was perpendicular to 
the direction of the external magnetic field and the measured magnetization. Figure $5 b$ shows three thermal hysteresis obtained in an equivalent way as for the powder sample. The first one (black curve) is measured with no electric field. The thermal hysteresis is a little narrower as for the powder sample with $T_{\text {(up) }}=354 \mathrm{~K}$ and $T_{\text {(down) }}=344 \mathrm{~K}$.

In the next step the electric field of $\approx 33 \mathrm{kV} / \mathrm{m}$ ( $50 \mathrm{~V}$ on 1.5 -mm-wide sample, red curve in Figure $5 \mathrm{~b})$ and $\approx 66 \mathrm{kV} / \mathrm{m}(100 \mathrm{~V}$ on 1.5 -mm-wide sample, blue curve in Figure $5 b)$ was applied during the magnetic measurements in the magnetic field of $500 \mathrm{Oe.}$
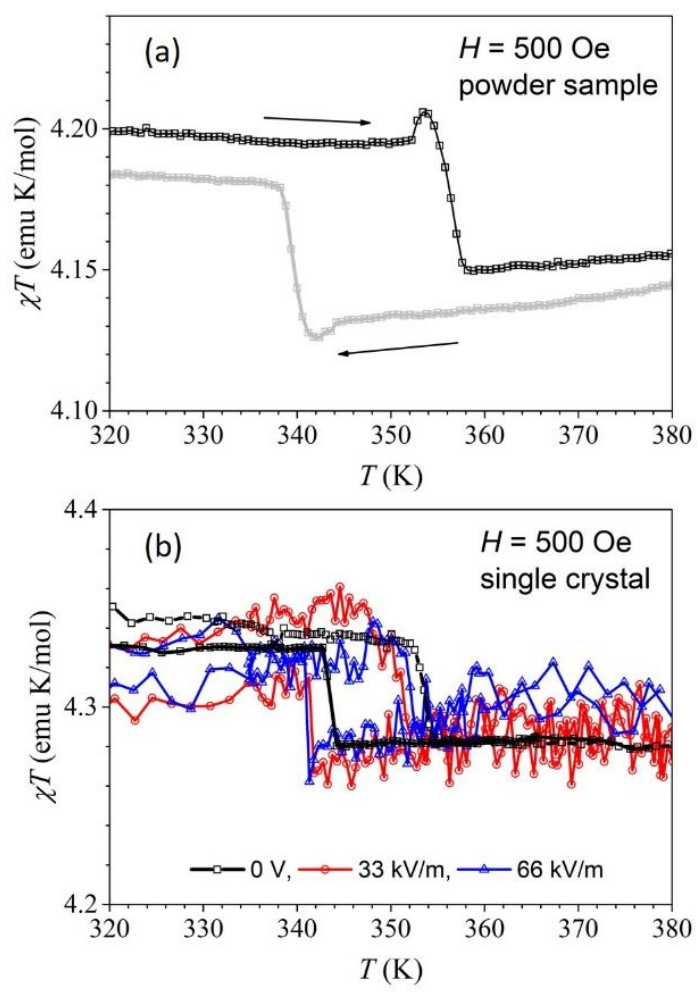
Figure 5. The product $\chi \cdot T$ as a function of the temperature for $\left[\mathrm{N}\left(\mathrm{C}_{2} \mathrm{H}_{5}\right)_{3} \mathrm{CH}_{3}\right]\left[\mathrm{FeCl}_{4}\right](\mathrm{a})$

powder, (b) single-crystal using different applied electric fields. The arrows in a show a direction of the temperature change, while in $b$ they show a change of the transition temperature $T_{\text {(up) }}$ due to the application of electric field.

Despite the increased noise in the presence of an electric field, a shift of both $T_{\text {(up) }}$ and $T_{\text {(down) }}$ for approximately $2 \mathrm{~K}$ to lower temperatures was observed for both applied electric fields and may be considered as direct evidence of the ME coupling.

\section{CONCLUSIONS}

The measurements underlying this research included a range of temperatureinduced XRPD, electrical and magnetic studies on a newfangled molecular ferroelectric $\left[\mathrm{N}\left(\mathrm{C}_{2} \mathrm{H}_{5}\right)_{3} \mathrm{CH}_{3}\right]\left[\mathrm{FeCl}_{4}\right]$. The crystal structure of ferroelectric $\left[\mathrm{N}\left(\mathrm{C}_{2} \mathrm{H}_{5}\right)_{3} \mathrm{CH}_{3}\right]\left[\mathrm{FeCl}_{4}\right]$ at ambient temperature was determined from the XRPD data, whereas the one of the transformed paraelectric phase was successfully indexed in centrosymmetric space group of higher symmetry. By deducing the symmetry-breaking from the Curie symmetry 
principle an Aizu notation of $6 / \mathrm{mmm} / 6 \mathrm{~mm}$ group was ascribed to the transformation from the paraelectric $P 6_{3} / m m c$ space group at $363 \mathrm{~K}$ to the ferroelectric $P 6_{3} m c$ space group at $296 \mathrm{~K}$ and $295 \mathrm{~K}$, respectively. The temperature dependence of the complex dielectric permittivity of $\left.\left[\mathrm{N}_{(} \mathrm{C}_{2} \mathrm{H}_{5}\right)_{3} \mathrm{CH}_{3}\right]\left[\mathrm{FeCl}_{4}\right]$ measured during the heating and cooling cycles corroborated the symmetry-breaking process as well as the non-centrosymmetric to centrosymmetric phase transition approaching $T_{\mathrm{c}}=363 \mathrm{~K}$, as observed from the XRPD patterns. Besides lighting up the groundbreaking influence of crystallographic information on the structure-property relationship, we ascertain two more things from the abovediscussed results: (1) a step-like shape of the dramatic anomaly at 100 and $600 \mathrm{kHz}$ in the dielectric permittivity observed during the heating and cooling runs directly proved the bistable dielectric property of $\left.\left[\mathrm{N}_{(} \mathrm{C}_{2} \mathrm{H}_{5}\right)_{3} \mathrm{CH}_{3}\right]\left[\mathrm{FeCl}_{4}\right]$, and (2) the presence of the coupled magnetic and electric orderings served as a key evidence of the ME response in $\left[\mathrm{N}\left(\mathrm{C}_{2} \mathrm{H}_{5}\right)_{3} \mathrm{CH}_{3}\right]\left[\mathrm{FeCl}_{4}\right]$.

The fully-scaled improper ferroelectric $\left[\mathrm{N}\left(\mathrm{C}_{2} \mathrm{H}_{5}\right)_{3} \mathrm{CH}_{3}\right]\left[\mathrm{FeCl}_{4}\right]$, showing an exceptionally high increase in the dielectric permittivity of about $360 \%$ at $100 \mathrm{kHz}$ above 
the ambient temperature and integrating the multiple physical bistability is surely a promising candidate with an application in design and development of novel ME devices.

Supporting Information. Further details of the crystal structure investigations may be obtained from the Fachinformationszentrum Karlsruhe, 76344 Eggenstein-Leopoldshafen (Germany), on quoting the CSD-434157 depository number.

\section{Conflicts of interest}

There are no conflicts to declare.

\section{ACKNOWLEDGEMENTS}

The financial support from the Slovenian Research Agency (research core funding No. P2-0348) and the National Research Council of Italy for the Short-term mobility program 2016 are gratefully acknowledged.

\section{AUTHOR INFORMATION}




\section{Corresponding Author}

*Martina Vrankić, e-mail: Martina.Vrankic@irb.hr

\section{REFERENCES}

1. Lines, M. E. and Glass, A. M. Principles and Application of Ferroelectrics and Related

Materials, Oxford University Press, Oxford, UK, 1977.

2. R. Ramesh, R. Emerging routes to multiferroics. Nature, 2009, 461, 1218-1219.

3. Rogez, G.; Viart, N. and Drillon, M. Multiferroic Materials: The Attractive Approach of

Metal-Organic Frameworks (MOFs). Angew. Chem. Int. Edit., 2010, 49, 1921-1923. 
4. Zhang, W. and Xiong, R. G. Ferroelectric Metal-Organic Frameworks. Chem. Rev.,

2012, 112, 1163-1195.

5. Cai, H.-L.; Zhang, Y.; Fu, D.-W.; Zhang, W.; Liu, T.; Yoshikawa, H.; Awaga, K. and

Xiong, R.-G. Above-room-temperature magnetodielectric coupling in a possible moleculebased multiferroic: triethylmethylammonium tetrabromoferrate(III). J. Am. Chem. Soc., 2012, 134, 18487-18490.

6. Gao, K.; Gu, M.; Qiu, X.; Ying, X. N.; Ye, H.-Y.; Zhang, Y.; Sun, J.; Meng, X.; Zhang, F. M.; Wu, D.; Cai, H.-L. and Wu, X. S. Above-room-temperature molecular ferroelectric and fast switchable dielectric of diisopropylammonium perchlorate. J. Mater. Chem. C, 2014, 2, 9957-9963.

7. Paliwoda, D.; Szafrański, M.; Hanfland, M. and Katrusiak, A. A giant 2-dimensional dielectric response in a compressed hydrogen-bonded hybrid organic-inorganic salt. J. Mater. Chem. C, 2018, 6, 7689-7699.

8. Mostovoy, M. and Cheong, S. W. Multiferroics: a magnetic twist for ferroelectricity. Nat. Mater., 2007, 6, 13-20. 
9. Ramesh, R. and Spaldin, N. A. Multiferroics: progress and prospects in thin films.

Nat. Mater., 2007, 6, 21-29.

10. Yang, C.; Dong, R.; Wang, M.; Petkov, P. St.; Zhang, Z.; Wang, M.; Han, P.;

Ballabio, M.; Bräuninger, S. A.; Liao, Z.; Zhang, J.; Schwotzer, F.; Zschech, E.; Klauss,

H.-H.; Cánovas, E.; Kaskel, S.; Bonn, M.; Zhou, S.; Heine, T. and Feng, X. A semiconducting layered metal-organic framework magnet. Nat. Commun., 2019, 10, 3260.

11. Han, J.; Nishihara, S.; Inoue, K. and Kurmoo, M. High Magnetic Hardness for the Canted Antiferromagnetic, Ferroelectric, and Ferroelastic Layered Perovskite-like $\left(\mathrm{C}_{2} \mathrm{H}_{5} \mathrm{NH}_{3}\right)_{2}\left[\mathrm{Fe}^{\prime \prime} \mathrm{Cl}_{4}\right]$. Inorg. Chem., 2015, 54, 2866-2874.

12. Zhang, Y.; Liao, W. Q.; Fu, D.-W.; Ye, H.-Y.; Liu, C.-M.; Chen, Z.-N. and Xiong, R.-G. The First Organic-Inorganic Hybrid Luminescent Multiferroic: (Pyrrolidinium) $\mathrm{MnBr}_{3}$. Adv. Mater., 2015, 26, 3942-3946.

13. Cui, Z.; Gao, K.; Liu, C.; Yin, Y.; Fu, D.-W.; Cai, H.-L. and Wu, X. S. Molecular Ferroelectric Pyridin-4-ylmethanaminium Perchlorate Undergoes Paraelectric- 
Ferroelectric and Ferroelectric-Ferroelectric Phase Transitions. J. Phys. Chem. C, 2016, $120,2925-2931$.

14. Zhang, H.-Y.; Wei, Z.; Li, P.-F.; Tang, Y.-Y.; Liao, W.-Q.; Ye, H.-Y.; Cai, H. and Xiong, R.-G. The Narrowest Band Gap Ever Observed in Molecular Ferroelectrics: Hexane-1,6- diammonium Pentaiodobismuth(III). Angew. Chem. Int. Edit., 2018, 57, 526.

15. Zhang, H.-Y.; Wei, Z.; Li, P.-F.; Tang, Y.-Y.; Liao, W.-Q.; Ye, H.-Y.; Cai, H. and Xiong, R.-G. The Narrowest Band Gap Ever Observed in Molecular Ferroelectrics: Hexane-1,6- diammonium Pentaiodobismuth(III). Angew. Chem., 2018, 130, 535.

16. Tang, Y.-Y.; Li, P.-F.; Liao, W.-Q.; Shi, P.-Ping; You, Y.-M. and Xiong, R.-G. Multiaxial Molecular Ferroelectric Thin Films Bring Light to Practical Applications. J. Am. Chem. Soc., 2018, 140, 8051-8059.

17. Tang, Z.; Gao, K.-G.; Sun, X.-F.; Yang, X.-M.; Wu, Y.-Z.; Gao, Z.-R.; Cai, H.-L. and Wu, X. S. High Temperature Molecular Ferroelectric Tris(2- Hydroxyethyl) Ammonium Bromide with Dielectric Relaxation. J. Phys. Chem. Lett., 2019, 10, 6650-6655. 
18. Li, D.; Zhao, X.-M.; Zhao, H.-X.; Long, L.-S. and Zheng, L.-S. Coexistence of MagneticOptic-Electric Triple Switching and Thermal Energy Storage in a Multifunctional Plastic Crystal of Trimethylchloromethyl Ammonium Tetrachloroferrate(III). Inorg. Chem., 2019, 58, 655-662.

19. Zhang, Y.; Ye, H. Y.; Cai, H. L.; Fu, D. W.; Ye, Q.; Zhang, W.; Zhou, Q.; Wang, J.;

Yuan, G. L. and Xiong, R.-G. Switchable Dielectric, Piezoelectric, and Second-Harmonic Generation Bistability in a New Improper Ferroelectric above Room Temperature. Adv.

Mater., 2014, 26, 4515-4520.

20. Altomare, A.; Cuocci, C.; Giacovazzo, C.; Moliterni, A.; Rizzi, R.; Corriero. N. and Falcicchio, A. EXPO2013: a kit of tools for phasing crystal structures from powder data. J. Appl. Cryst., 2013, 46, 1231-1235.

21. Larson, A. C. and Von Dreele, R. B. General Structure Analysis System (GSAS). Los Alamos National Laboratory Report LAUR, 2004, 86-748.

22. Toby, B. H. EXPGUI, a graphical user interface for GSAS. J. Appl. Cryst., 2001, 34, 210213.

23. X'Pert HighScore Plus Program, Version 4.1, PANalytical B. V., Almelo:

Netherlands, 2014. 
24. Bain, G. A. and Berry, J. F. Diamagnetic Corrections and Pascal's Constants. J.

Chem. Educ., 2008, 85, 532-536.

25. Grimmer, H. The forms of tensors describing magnetic, electric and toroidal properties. Ferroelectrics, 1994, 161, 181-189.

26. Nye, J. F. Physical Properties of Crystals: Their Representation by Tensors and Matrices, Oxford University Press, New York, 2000.

27. Petrina, A.; Petricek, V.; Maly, K.; Subrtova, V.; Linek, A. and Hummel, L. The crystal and molecular structure of Methyltriethylammonium $\mu$-8,8'-oxa-3,3'-commo-bis(undecahydro-1,2dicarba-3-cobalta-closo-dodecaborate) (1-), $\left[\mathrm{N}\left(\mathrm{C}_{2} \mathrm{H}_{5}\right)_{3} \mathrm{CH}_{3}\right]^{+}$. $\left[\mathrm{O}\left(\mathrm{C}_{2} \mathrm{~B}_{9} \mathrm{H}_{10}\right)_{2} \mathrm{Co}\right]^{-}$. Z. Kristallogr., 1981, 154, 217-226.

28. Vettier, C. and Yelon, W. B. The structure of $\mathrm{FeCl}_{2}$ at high pressures. J. Phys. Chem.

Solids, 1975, 36, 401-405.

29. Howard, C. J. The approximation of asymmetric neutron powder diffraction peaks by sums of Gaussians. J. Appl. Cryst., 1982, 15, 615-620.

30. Thompson, P.; Cox, D. E. and Hastings, J. B. Rietveld refinement of Debye-Scherrer synchrotron X-ray data from $\mathrm{Al}_{2} \mathrm{O}_{3}$. J. Appl. Cryst., 1987, 20, 79-83. 
31. Evans, D. J.; Hills, A.; Hughens, D. L. and Leigh, G. J. Structures of tetraethylammonium tetrachloroferrate(III) and the mixed halide iron(III) complex, $\left[\mathrm{NEt}_{4}\right]\left[\mathrm{FeBrCl}_{3}\right]$. Acta Cryst. C, 1990, 46, 1818-1821.

32. Cotton, F. A. and Murillo, C. A. Structure of Tetraphenylarsonium Tetrachloroferrate(III). Inorg. Chem., 1975, 14, 2467-2469.

33. Momma, K.; Izumi, F. VESTA 3 for three-dimensional visualization of crystal, volumetric and morphology data. J. Appl. Crystallogr. 2011, 44, 1272-1276.

34. Shi, P.-P.; Ye, Q.; Li, Q.; Wang, H.-T.; Fu, D.-W.; Zhang, Y. and Xiong, R.-G. Novel PhaseTransition Materials Coupled with Switchable Dielectric, Magnetic, and Optical Properties: $\left[\left(\mathrm{CH}_{3}\right)_{4} \mathrm{P}\right]\left[\mathrm{FeCl}_{4}\right]$ and $\left[\left(\mathrm{CH}_{3}\right)_{4} \mathrm{P}\right]\left[\mathrm{FeBr}_{4}\right]$. Chem. Mater., 2014, 26, 6042-6049.

35. Aizu, K. Possible Species of Ferromagnetic, Ferroelectric, and Ferroelastic Crystals. Phys. Rew. B, 1970, 2, 754-772.

36. Mitsui, T.; Tatsuzaki, I. and Nakamura, E. An Introduction to the Physics of Ferroelectrics, Gordon and Breach Science Publishers, New York, 1976.

37. Smolenskii, G. A.; Bokov, V. A.; Isupov, V. A.; Krainik, N. N.; Pasinkov, R. E. and Sokolov, I. A. Ferroelectrics and Related Materials, Gordon and Breach Science Publisher, New York, 1984. 
38. Fridkin, V. and Ducharme, S. Ferroelectricity at the Nanoscale Basics and Applications, Springer-Verlag Berlin Heidelberg, 2014.

39. Mabbs, F. E. and Machin, D. J. Magnetism and Transition Metal Complexes, Dover

Publications, Inc. Mineola, New York, 1973.

40. Ashcroft, N. W. and Mermin, N.D. Solid State Physics, Saunders College Publishing, USA, 1976.

41. Ning, W. H.; Chen, X. R.; Liu, J. L.; Guo, P. C. and Ren, X. M. Two magnetic phase transitions, driven by symmetry breaking and isostructural phase transitions, in a nickel-bis-dithiolene spin system. New J. Chem., 2014, 38, 179-188.

42. Aguirre, L. C. G.; Doldan, B. P.; Mira, J.; Garcia, .; S. C.; Rodriguez, M. A. S.; Andujar, M. S.; Singleton, J. and Zapf, V. S. Magnetic Ordering-Induced Multiferroic Behavior in $\left[\mathrm{CH}_{3} \mathrm{NH}_{3}\right]\left[\mathrm{Co}(\mathrm{HCOO})_{3}\right]$ Metal-Organic Framework. J. Am. Chem. Soc., 2016, 138, 1122-1125.

43. Li, W.; Wang, Z. M.; Deschler, F.; Gao, S. and Friend, R. H. Chemically diverse and multifunctional hybrid organic-inorganic perovskites. Nat. Rev., 2017, 2, 16099.

44. Maczka, M.; Gagor, A.; Ptak, M.; Paraguassu, W.; Silva, T. A.; Sieradzki, A. and Pikul, A. Phase Transitions and Coexistence of Magnetic and Electric Orders in the Methylhydrazinium Metal Formate Frameworks. Chem. Mater., 2017, 29, 2264-2275. 
45. Asha, K. S.; Ahmed, N.; Nath, R.; Kuznetsov, D. and Mandal, S. Impact of Postsynthetic Modification on the Electrical and Magnetic Properties of Materials. Inorg. Chem., 2017, 56, 73167319.

46. Han, S.; Zhang, J.; Teng, B.; Ji, C.; Zhang, W.; Sun, Z. and Luo, J. Inorganic-organic hybrid switchable dielectric materials with the coexistence of magnetic anomalies induced by reversible hightemperature phase transition. J. Mater. Chem. C, 2017, 5, 8509-8515.

47. Kahn, O. Molecular Magnetism, VCH Publishing, 1993.

48. Xu, G. C.; Zhang, W.; Ma, X. M.; Chen, Y. H.; Zhang, L.; Cai, H. L.; Wang, Z. M.; Xiong, R. G. and Gao, S. Coexistence of Magnetic and Electric Orderings in the Metal-Formate Frameworks of $\left[\mathrm{NH}_{4}\right]\left[\mathrm{M}(\mathrm{HCOO})_{3}\right] . J$. Am. Chem. Soc., 2011, 133, 14948-14951.

49. Zhang, B.; Zhang, Y. and Zhu, D. $\left[\left(\mathrm{C}_{2} \mathrm{H}_{5}\right)_{3} \mathrm{NH}\right]_{2} \mathrm{Cu}_{2}\left(\mathrm{C}_{2} \mathrm{O}_{4}\right)_{3}$ : a three-dimensional metal-oxalato framework showing structurally related dielectric and magnetic transitions at around 165 K. Dalton Trans., 2012, 12, 8509-8511.

50. Stroppa, A.; Barone, P.; Jain, P.; Mato, J. M. P. and Picozzi, S. Hybrid Improper Ferroelectricity in a Multiferroic and Magnetoelectric Metal-Organic Framework. Adv. Mater., 2013, 25, 2284-2290.

51. Shang, R.; Chen, S.; Wang, Z. M. and Gao, S. A Copper-Formate Framework Showing a Simple to Helical Antiferroelectric Transition with Prominent Dielectric Anomalies and Anisotropic Thermal Expansion, and Antiferromagnetism. Chem. - Eur. J., 2014, 20, 1587215883. 


\section{"For Table of Contents Only"}
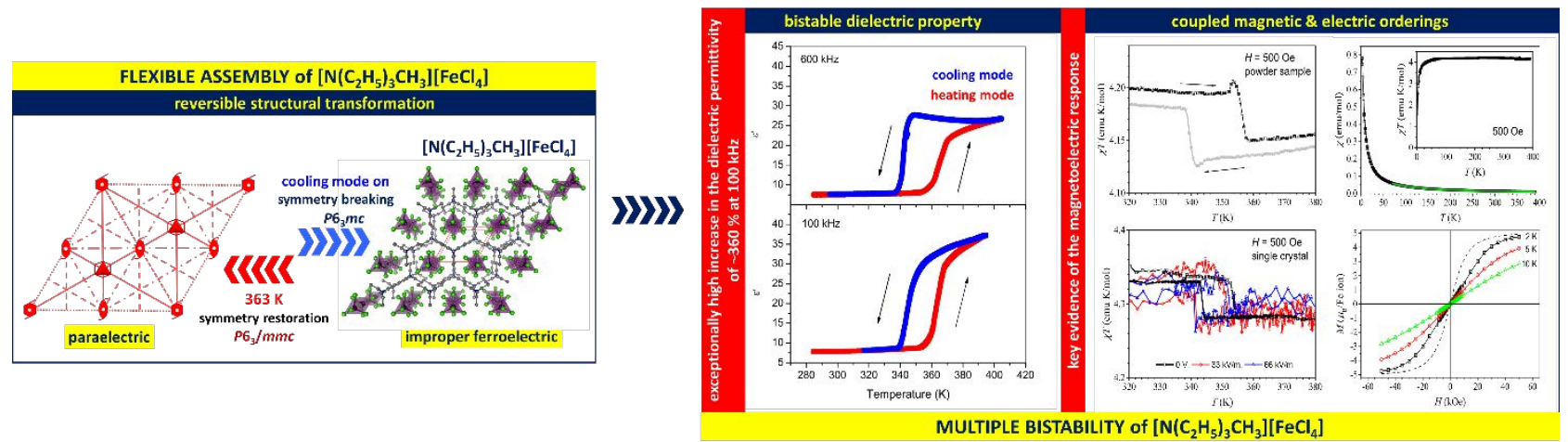

\section{SYNOPSIS}

An organic-inorganic material $\left[\mathrm{N}_{(}\left(\mathrm{C}_{2} \mathrm{H}_{5}\right)_{3} \mathrm{CH}_{3}\right]\left[\mathrm{FeCl}_{4}\right]$ with multiple bistable characteristics

was prepared in powder form. Improper ferroelectric architecture of $\left[N\left(\mathrm{C}_{2} \mathrm{H}_{5}\right)_{3} \mathrm{CH}_{3}\right]\left[\mathrm{FeCl}_{4}\right]$

possesses considerable flexibility by joining an outstanding progressive increase of

dielectric permittivity across temperature-triggered cycles and magnetically modulated

physical properties resulting in magnetoelectric response. Reversible phase transitions due to the crystal symmetry transforming from paraelectric space group $P 6_{3} / m m c$ at 363

$\mathrm{K}$ to ferroelectric space group $P{ }^{3} m c$ at $\mathrm{RT}$, imply a group-subgroup interlink unveiled from the XRPD data. 
